\title{
Surface-Bound Proteins with Preserved Functionality
}

\author{
Jiandi Wan, ${ }^{1,2}$ Marlon S. Thomas, ${ }^{1}$ Sean Guthrie, ${ }^{1}$ and Valentine I. Vullev ${ }^{1}$ \\ ${ }^{1}$ Department of Bioengineering, University of California, Riverside, A-220 Bourns Hall, Riverside, CA 92521, USA; and \\ ${ }^{2}$ Division of Engineering and Applied Sciences, Harvard University, Cambridge, MA 02138, USA
}

(Received 5 November 2007; accepted 9 March 2009; published online 24 March 2009)

\begin{abstract}
Biocompatibility of materials strongly depends on their surface properties. Therefore, surface derivatization in a controllable manner provides means for achieving interfaces essential for a broad range of chemical, biological, and medical applications. Bioactive interfaces, while manifesting the activity for which they are designed, should suppress all nonspecific interaction between the supporting substrates and the surrounding media. This article describes a procedure for chemical derivatization of glass and silicon surfaces with polyethylene glycol (PEG) layers covalently functionalized with proteins. While the proteins introduce the functionality to the surfaces, the PEGs provide resistance against nonspecific interactions. For formation of aldehyde-functionalized surfaces, we coated the substrates with acetals (i.e., protected aldehydes). To avoid deterioration of the surfaces, we did not use strong mineral acids for the deprotection of the aldehydes. Instead, we used a relatively weak Lewis acid for conversion of the acetals into aldehydes. Introduction of $\alpha, \omega$-bifunctional polymers into the PEG layers, bound to the aldehydes, allowed us to covalently attach green fluorescent protein and bovine carbonic anhydrase to the surfaces. Spectroscopic studies indicated that the surface-bound proteins preserve their functionalities. The surface concentrations of the proteins, however, did not manifest linear proportionality to the molar fractions of the bifunctional PEGs used for the coatings. This finding suggests that surface-loading ratios cannot be directly predicted from the compositions of the solutions of competing reagents used for chemical derivatization.
\end{abstract}

Keywords-Bioinert, Bioactive, Surface, Interface, Enzyme, Carbonic anhydrase, Fluorescence, Kinetics, Aldehyde deprotection, Silanization, Passivation.

\section{ABBREVIATIONS}

BCA Bovine carbonic anhydrase

C Volume concentration

CPS Counts per second

GFP Green fluorescence protein

NP 4-nitrophenol and 4-nitrophenolate

NPA 4-nitrophenolacetate

Address correspondence to Valentine I. Vullev, Department of Bioengineering, University of California, Riverside, A-220 Bourns Hall, Riverside, CA 92521, USA. Electronic mail: vullev@ucr.edu

\begin{tabular}{|c|c|}
\hline PEG & $\begin{array}{l}\text { Polyethylene glycol = polyethylene oxide } \\
(\text { PEO) }\end{array}$ \\
\hline$R_{\mathrm{DM}}$ & $\begin{array}{l}\text { Reaction fraction of diamine PEG } \\
\text { (equation 1) }\end{array}$ \\
\hline SAM & Self assembled monolayers \\
\hline$v_{i}$ & Initial reaction rate (i.e., rate at time 0 ) \\
\hline$\Gamma$ & Surface concentration \\
\hline$\lambda$ & Wavelength \\
\hline$\lambda_{\mathrm{em}}$ & Emission wavelength \\
\hline$\lambda_{\mathrm{ex}}$ & Excitation wavelength \\
\hline$\chi$ & Surface molar fraction \\
\hline
\end{tabular}

\section{INTRODUCTION}

This article describes a study on covalent attachment of proteins to glass and silica surfaces, chemically modified with polyethylene glycol (PEG). Due to the sensitivity of glass surfaces to strong acids and bases, we utilized cation-catalyzed deprotection of surfacebound aldehydes (instead of using strong acids). Introduction of $\alpha, \omega$-bifunctional polymers to the coatings allowed for covalent attachment of proteins to the PEGylated surfaces. Spectroscopic studies indicated that the surface-bound proteins preserve their functionality. The surface concentrations of the proteins, however, were not linearly proportional to the molar fractions of the bifunctional PEGs.

Bioinert interfaces that resist protein adsorption and cell adhesion are a key component in the development of biomaterials. ${ }^{20,33,35,76}$ Such nonfouling surfaces, however, are limiting for numerous biomedical applications, for which selected interactions with the biological media are required. Alternatively, controlled derivatization of bioinert surfaces with small molecules, ${ }^{15,41,49}$ polypeptides ${ }^{9,23,51,63,79}$ or oligo and polysaccharides ${ }^{60}$ yields interfaces that mediate biospecific interactions and suppress nonspecific interactions. ${ }^{32}$

Physisorption of proteins onto solid substrates is a facile and expedient method for preparation of nonfouling and even, bioactive interfaces. ${ }^{1,25,27-29,38,39,68,85}$ 
Such nonspecific adsorption of proteins, however, can lead to their partial or complete denaturation resulting in losses in their functionality. ${ }^{26}$ Furthermore, physisorbed coatings are susceptible to loss or replacement of their components due to desorption or competitive binding. ${ }^{26,70}$ Therefore, covalent attachment of the surface coatings to the supporting substrates is a preferred approach for surface engineering.

Chemical derivatization of surfaces with noncharged water-soluble oligomers and polymers, which do not contain hydrogen-bond donating groups, tends to produce bioinert interfaces. ${ }^{8,16}$ Observed exceptions to this general rule, such as formation of bioinert layers from zwitterionic ${ }^{10,11}$ and hydroxyl-terminated oligomers, ${ }^{8,24}$ however, indicate that this field of surface engineering is largely unexplored.

The exact mechanism of interaction (or suppression of the interactions) between polyethylene glycol (PEG) conjugates and biological molecules is not yet completely understood. 22,31,64 It is believed that the hydration of the PEG chains dictates its nonfouling characteristics. In aqueous media, PEG assumes helical conformation, in which the distance between neighboring ether oxygens, $\sim 0.29 \mathrm{~nm}$, is similar to the average separation between the oxygens in liquid water. ${ }^{6,88}$ This match in oxygen-oxygen distances favors the intercalation of the PEG chains into the hydrogenbonding network of bulk water. The hydration of the PEG molecules, hence, "insulates" their hydrophobic ethylene groups without disrupting the bulk water structure. In aqueous media, therefore, biological molecules in a close proximity with the PEG chains do not truly experience the presence of the polymer. Covalent attachment of layers of poly- and oligoethylene glycols to various solid substrates, indeed, presents a broadly chosen approach for engineering of nonfouling interfaces. ${ }^{3,37,40,43,48,67}$ PEGylated surfaces demonstrate some of the highest protein resistance; they are relatively durable; and chemically, PEGs are relatively easy to manipulate. ${ }^{40,52,58}$

Utilizing self-assembled monolayers (SAMs) of alkylthiols on gold surfaces for engineering of bioactive interfaces has gained significant popularity due to the simplicity of the used chemistry ${ }^{45,74}$ and to the availability of high-resolution structural information for such SAMs. ${ }^{80}$ Furthermore, engineering of bioactive interfaces over thin metal films has been a driving force for the development of biosensing applications based on surface plasmon resonance techniques. ${ }^{50,66,86,87}$

Surface engineering based on thiol chemistry on coinage metals, however, presents certain limitations. The requirement for coating the substrates with gold, silver or another noble metal compromises the cost efficiency of thiol-chemistry procedures. The metal coatings add undesired opacity to transparent substrates. The susceptibility of sulfur-gold conjugates to oxidation tends to compromise the durability and structural integrity of alkylthiol SAMs. Therefore, if chemically possible, a direct attachment of the surface coatings to the supporting substrate (instead of using thin layers of gold or silver) present a preferred approach for engineering of bioactive interfaces for a broad number of applications.

In previous examples of enzymatic activity from surface-bound proteins, the attachment of the enzymes to the PEGylated surfaces involves non-covalent interactions, such as proteins-ligand association ${ }^{86}$ or metalion chelation. ${ }^{7}$ Such non-covalent bonds are the weakest links in the chains holding the biological macromolecules to the substrate surfaces. Furthermore, the size of the complexes, which can provide non-covalent interactions with acceptable strength (e.g., streptavidinbiotin), is quite large and can even exceed the size of the proteins that they hold to the surface (e.g., the molecular weights of avidin and streptavidin are about 60 and 67$68 \mathrm{kDa}$, respectively). Covalent bonds are significantly smaller and stronger than the non-covalent complexes used for biocompatible interfaces. Therefore, our goal is to covalently attach globular proteins to silica-based surfaces and to demonstrate that they preserve their functionality via enzymatic assays.

The widely used biotin-(strept)avidin interaction for non-covalent attachments, for example, provides bonding strength of about $0.8 \mathrm{eV}$ (i.e., dissociation constant ranging between 1 and $100 \mathrm{fM}) .{ }^{5,42}$ The energy of a single (sigma) covalent bond between carbon and carbon, carbon-nitrogen, and carbon-oxygen, on the other hand, ranges between about 140 and $150 \mathrm{~kJ} / \mathrm{mol}$, which corresponds to about $1.5 \mathrm{eV}$. This twofold difference between the energies of covalent and non-covalent bonding interactions, results in more than ten-orders-of-magnitude difference between their dissociation rate constants. Under external pulling forces typical for biological macromolecular and cellular systems, therefore, while the non-covalent complexes have finite lifetimes, the covalent bonds are practically indissociable. ${ }^{12,13,18,36,65,82}$

The expanding demands of biophotinic and bioelectronic engineering poses requirements for the development of bioactive coatings on materials such as silicate glasses and silicon. ${ }^{33}$ Herein, we demonstrate a method for generation of protein-functionalized coatings directly anchored to the surfaces of glass and silicon (Scheme 1). All components of the coatings are covalently attached to each other and to the substrate. In particular, the proteins are attached directly to the substrate via chains with predetermined lengths. The surface-bound proteins manifested activity similar to the activity of the same proteins when free in solution. Fluorescence measurements and enzymatic assays 

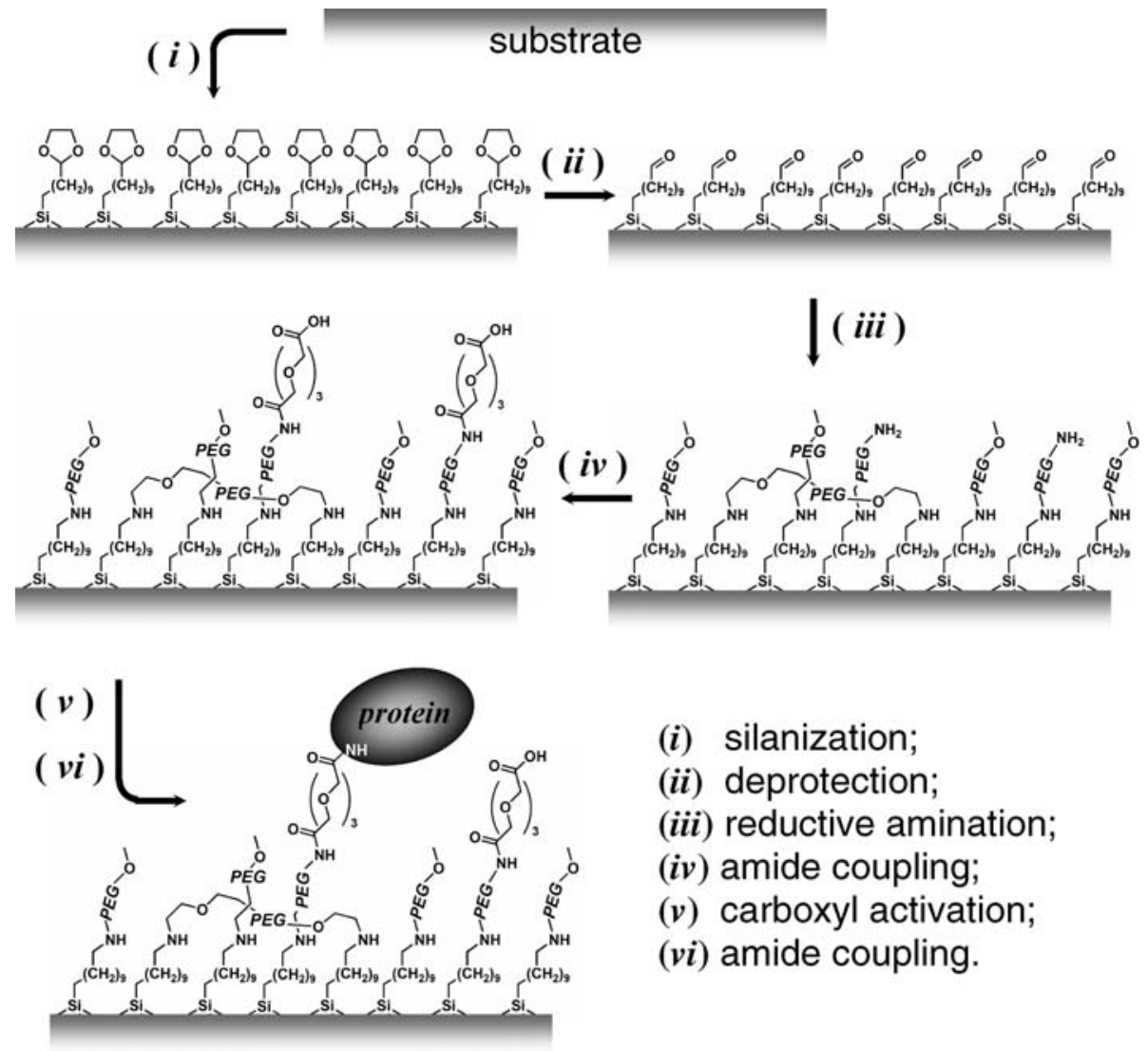

(i) silanization;

(ii) deprotection;

(iii) reductive amination;

(iv) amide coupling;

(v) carboxyl activation;

(vi) amide coupling.

SCHEME 1. Surface derivatization of a silica-based substrate, such as glass or $\mathrm{SiO}_{2}$-coated silicon.

allowed us to determine the dependence of the protein surface concentrations on the composition of the polymer mixture used for the bioinert layers.

In order to assure densely packed coatings, we used chemical reactions that do not involve bulky intermediates in the procedures for the preparation of the bioinert PEG layers. In addition, we demonstrated a unique and unprecedented method for deprotection of aldehydes, bound to glass surfaces, under relatively mild non-acidic condition. Because glass surfaces are susceptible to strongly acidic media, the traditionally used mineral acids for aldehyde deprotection cannot be applied for treatment of organic coatings on glass substrates. The described surface derivatization encompasses methodology with the potential for a broad use for rational design and engineering of bioactive interfaces on silica-based materials.

\section{MATERIALS AND METHODS}

\section{Materials}

Pre-cleaned microscope glass slides (Corning; $75 \times 50 \mathrm{~mm}$; about $73 \% \mathrm{SiO}_{2}, 14 \% \mathrm{Na}_{2} \mathrm{O}, 7 \% \mathrm{CaO}$,
$4 \% \mathrm{MgO}$, and $2 \% \mathrm{Al}_{2} \mathrm{O}_{3}$ ) were purchased from VWR and cut into $25 \times 8 \mathrm{~mm}$ pieces prior to use. Polished test grade silicon $<100>$ wafers were purchased from Silicon Sense, Inc. and also cut into $25 \times 8 \mathrm{~mm}$ pieces. 11-(Trietoxysilyl) undecanaldehyde acetal was purchased from Gelest, Inc. Indium (III) chloride (99.999\%), redistilled $N, N$-Diisopropylethylamine (DIPEA) and sodium cyanoborohydride were all purchased from Aldrich. 3,6,9-Trioxaundecanedioic acid was obtained from Fluka. $N, N$-Diisopropylcarbodiimide (DIC) and $N$-hydroxysuccinimide (HOSu) were obtained from Lancaster. Anhydrous hydroxybenzotriazole $(\mathrm{HOBt})$ was purchased from Chem-Impex International. Toluene, tetrahydrofuran (THF), and methanol, spectroscopy grade and anhydrous, were obtained from VWR and Fisher. Ethanol (dehydrated, 200 proof) was purchased from Pharmco. $\alpha, \omega$-Diamino polyethylene glycol $\left(\mathrm{NH}_{2}-\mathrm{PEG}-\mathrm{NH}_{2}\right)$ and methoxy amino polyethylene glycol (MeO-PEG- $\mathrm{NH}_{2}$ ), $\mathrm{MW}=2000$, were purchased from Nectar. Green fluorescent protein (GFP) was obtained from Upstate Signaling Solutions. Bovine carbonic anhydrase II (BCA) and 4-nitrophenyl acetate were obtained from Sigma. 


\section{Surface Derivatization Procedures}

The silicon wafers were cut and used without further cleaning with solutions. Prior to film preparation, the glass slides were cleaned by using ultrasonic treatment in toluene, dichloromethane, ethanol, ethanol:concentrated $\mathrm{HCl}(1: 1, \mathrm{v} / \mathrm{v})$, and rinsed with copious amounts of deionized water (MilliQ $18 \Omega$ ).

The surfaces of the glass and silicon substrates were blown dry with high-purity nitrogen and treated with oxygen plasma for $10 \mathrm{~min}$ prior the silanization. This treatment yields a hydrophilic surface with a native oxide layer.

\section{Silanization (Scheme 1, i)}

Five oxygen-plasma treated substrate slides were immersed in $10 \mathrm{~mL}$ solution of $0.04 \%$ (v/v) of one of 11-(trietoxysilyl)undecanaldehyde acetal and $0.02 \%$ (v/v) $N, N$-diisopropylethylamine (DIPEA) in anhydrous toluene. The glass chambers used for this treatment offered a configuration that prevents the surfaces of the slides to touch one another or the walls of the chamber. The chamber with slides and silanization solution was heated on a sand bath and $1 \mathrm{~h}$ after the solution temperature reached $110^{\circ} \mathrm{C}$, it was sonicated for 60 . After overnight heating at $110^{\circ} \mathrm{C}$, the slides were removed from the solution and doubly washed with toluene, dichloromethane, THF and ethanol $(10 \mathrm{~mL}$ each), as well as with plenty of deionized water. The modified glass slides were kept immersed in deionized water and further derivatized within a twoday period.

\section{Aldehyde Deprotection (Scheme 1, ii)}

The acetal-coated substrates were taken out of deionized water, blown dry with ultra pure nitrogen and immersed in a $10 \mathrm{~mL}$ methanol and water solution $(1: 1, \mathrm{v} / \mathrm{v})$ containing $2 \mathrm{mg} \mathrm{InCl}_{3}{ }^{61}$ The solution was heated to $80{ }^{\circ} \mathrm{C}$. After keeping it at this temperature for $1.5 \mathrm{~h}$, the reaction mixture was allowed to cool down to room temperature and the substrate slides were taken out of the solution, washed and used immediately.

\section{Amine-Functionalized Polyethylene Glycol Layers (Scheme 1, iii)}

Washed substrates with freshly deprotected aldehyde groups were blown dry and immediately immersed into a $10 \mathrm{~mL}$ methanol solution of diamino polyethylene glycol $\left(\mathrm{NH}_{2}-\mathrm{PEG}-\mathrm{NH}_{2}\right) R_{\mathrm{DM}} \times 30 \mathrm{mg}$ ( $\mathrm{MW}=2 \mathrm{kDa})$ and methoxy amino polyethylene glycol $\left(\mathrm{MeO}-\mathrm{PEG}-\mathrm{NH}_{2}\right)\left(1-R_{\mathrm{DM}}\right) \times 30 \mathrm{mg}(\mathrm{MW}=$ $2 \mathrm{kDa}$ ). The mixture was allowed to react for half an hour at room temperature and then sodium cyanoborohydride $(20 \mathrm{mg}, 30 \mathrm{mmol})$ was added to the solution. The mixture was shaken and reacted for additional $48 \mathrm{~h}$ at room temperature. The slides were removed from the solution and doubly washed with $10 \mathrm{~mL}$ methanol, THF, and $100 \mathrm{~mL}$ deionized water. Slides with $R_{\mathrm{DM}}$ between 0 and 0.2 were prepared. All the modified substrates were stored in deionized water at $4{ }^{\circ} \mathrm{C}$ till use.

\section{Carboxylate-Functionalized Polyethylene Glycol Layers (Scheme 1, iv)}

Substrates with amine functionalized PEG layers were blown dry and put into $10 \mathrm{~mL}$ dry THF with 3,6,9-trioxaundecanedioic acid (30 $\mathrm{mg}, 0.14 \mathrm{mmol})$, HOBt ( $25 \mathrm{mg}, 0.18 \mathrm{mmol})$, DIC (0.1 mL), and DIPEA $(0.05 \mathrm{~mL})$. The mixture was shaken at room temperature overnight in the absence of light. The substrate slides were then removed and doubly washed with THF and deionized water.

\section{Covalent Attachment of Proteins to Polyethylene Glycol} Layers (Scheme 1, v and vi)

Substrates with PEG layers functionalized with carboxylic acid groups were blown dry and placed in $10 \mathrm{~mL}$ dry THF solution of HOSu (20 mg, $0.17 \mathrm{mmol})$ and DIC $(0.1 \mathrm{~mL})$. The mixture was allowed to react at room temperature overnight in the absence of light. The activated substrates, i.e., the slides with the active $\mathrm{OSu}$ esters on their surfaces, were removed from the THF solution, doubly washed with dry THF, blown dry with nitrogen and immediately placed into a $10 \mathrm{~mL}$ PBS (phosphate-buffered saline) buffer $(\mathrm{pH}=6.85)$ solution containing $5 \mathrm{mg}$ protein (GFP or BCA, Figs. 1a and 1b, respectively). The mixture was allowed to react for $24 \mathrm{~h}$ at room temperature at constant shaking. The slides were removed from the solution and washed with copious amounts of deionized water (MilliQ $18 \mathrm{M} \Omega$ ) and PBS buffer. The modified substrate slides were kept in PBS buffer solution $(\mathrm{pH}=6.85)$ at $4{ }^{\circ} \mathrm{C}$ and used no latter than one day after the preparation.

\section{Surface Characterization}

The chemical composition of the surfaces was characterized with X-ray photoelectron spectroscopy and the thicknesses of the layers on the silicon substrates were determined using ellipsometry.

\section{X-ray Photoelectron Spectroscopy (XPS)}

$\mathrm{X}$-ray photoelectron spectroscopy was performed with an SSX 100 ESCA spectrometer with monochromatized AlK $\alpha$ source $(1486.6 \mathrm{eV})$. Survey spectra 

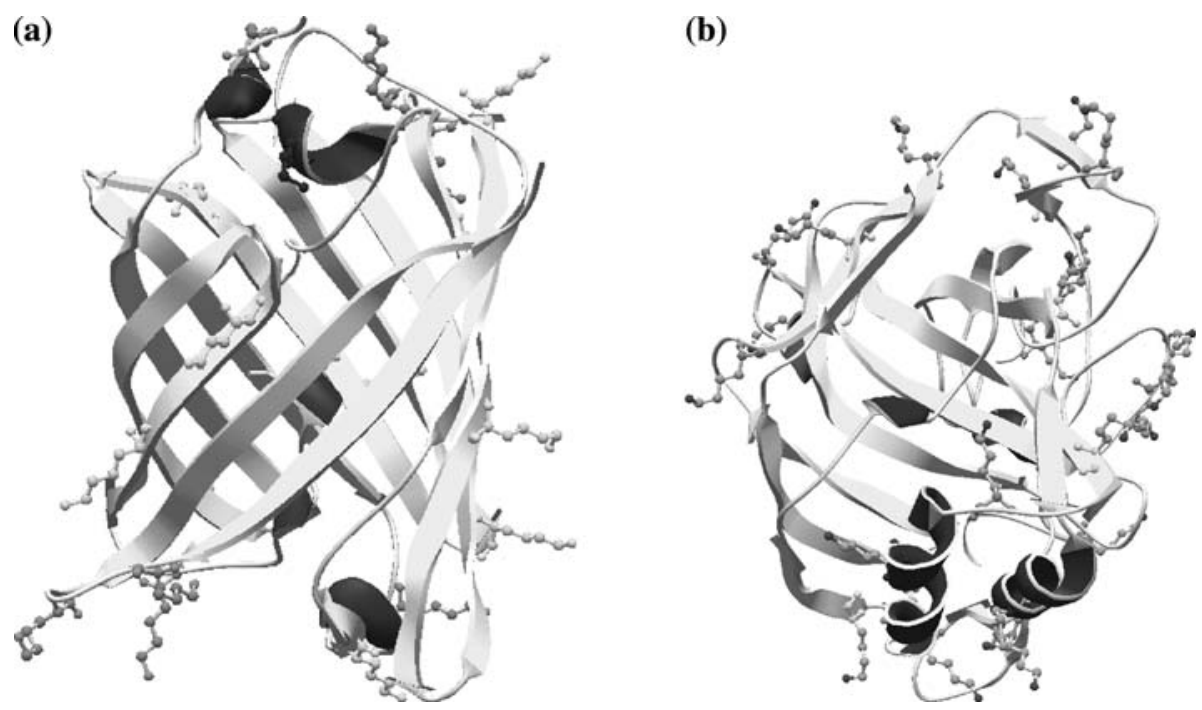

FIGURE 1. Ribbon representation of the structures of (a) models. (From the protein data bank, http://www.pdb.org/).

TABLE 1. Surface element composition for glass substrates coated with layers with various functionalities.

\begin{tabular}{lcccc}
\hline & $\% \mathrm{Si}$ & $\% \mathrm{O}$ & $\% \mathrm{C}$ & $\% \mathrm{~N}$ \\
\hline Blank & 24 & 70 & 5.4 & - \\
Acetal & 19 & 58 & 23 & - \\
Aldehyde & 14 & 64 & 22 & - \\
PEG & 14 & 50 & 32 & 4.0 \\
\hline
\end{tabular}

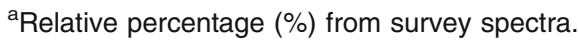

were collected from 0 to $1000 \mathrm{eV}$ with pass energy of $188 \mathrm{eV}$, and high resolution spectra were collected for each element detected with pass energy of $23.5 \mathrm{eV}$. Survey and high-resolution spectra were collected at $65^{\circ}$ take off angle, defined as the angle spanned by the electron path to the analyzer and the sample surface. All spectra were referenced by setting the carbon $\mathrm{C} 1 \mathrm{~s}$ peak to $285.0 \mathrm{eV}$ to compensate for residual charging effects. The peaks as a shift of $-1.5 \mathrm{eV}$ and $-3 \mathrm{eV}$ from the $\mathrm{C}-\mathrm{C}$ peak is the characteristic PEG coupling $\mathrm{C}-\mathrm{O}$ peak and aldehyde $\mathrm{C}=\mathrm{O}$ peak, respectively. ${ }^{21}$ Spectral analysis was performed using the software proved with the XPS instrument. Percents of atomic composition and atomic ratios were corrected using sensitivity factor incorporated in the software. The high-resolution $\mathrm{C}$ ls peaks were deconvoluted by a fit to a linear sum of Gaussians and a baseline correction.

Table 1 highlights the surface elemental composition extracted from analysis of survey spectra for glass surfaces coated with layers with various functionalities. Table 2 contains the results from the analysis of the $\mathrm{C} 1 \mathrm{~s}$ high-resolution spectra for the same substrates.

The decrease in the relative amount of $\mathrm{C}-\mathrm{O}$, accompanied with an increase in the relative amount of
TABLE 2. Surface carbon composition for glass substrates coated with layers with various functionalities. ${ }^{a}$

\begin{tabular}{lrcc}
\hline & $\% \mathrm{C}-\mathrm{C}$ & $\% \mathrm{C}-\mathrm{O}$ & $\% \mathrm{C}=\mathrm{O}^{\mathrm{b}}$ \\
\hline Blank & 100 & - & - \\
Acetal & 67 & 23 & 9.8 \\
Aldehyde & 70 & 15 & 16 \\
PEG & 66 & 32 & 2.2 \\
\hline
\end{tabular}

${ }^{\mathrm{a}}$ Relative percentage (\%) from high-resolution $\mathrm{C} 1 \mathrm{~s}$ spectra.

${ }^{\mathrm{b}}$ The $\mathrm{C} 1 \mathrm{~s}$ binding energy for $\mathrm{C}=\mathrm{O}$ and $\mathrm{O}-\mathrm{C}-\mathrm{O}$ are indiscernible.

$\mathrm{C}=\mathrm{O}$, upon deprotection of the aldehydes (i.e., transformation of acetals to aldehydes) is indicative for the chemical removal of the ethylene glycol protection group in the acetal. ${ }^{21}$ The appearance of nitrogen peak and the increase in the relative amount of $\mathrm{C}-\mathrm{O}$, with concurrent decrease in the relative amount of $\mathrm{C}=\mathrm{O}$, are indication for the successful coupling of the PEG to the aldehyde surface via reductive amination. ${ }^{59}$ The chemical surface reaction conducted on silicon substrates showed identical trend.

\section{Ellipsometry}

Ellipsometric measurements, conducted in air, were performed at 44 wavelengths $(\lambda)$ between 400 and $700 \mathrm{~nm}$ and at three angles of incidence $(\theta)$ using M-44 spectroscopic ellipsometer, J. A. Woollam Co., Inc. The phase $(\Delta)$, and the amplitude $(\Psi)$ were determined with uncertainty of less than $0.005^{\circ}, 0.02^{\circ}$, and $0.01^{\circ}$, respectively, for three different angles, $\theta=60^{\circ}, 70^{\circ}$, and $80^{\circ}$. The complex refractive index $(n=n+i k)$ and layer thickness $(d)$ were obtained from fits of $\Delta$ and $\Psi$ vs. $\lambda$ and $\theta$, using a Newton-Raphson solution of Fresnel's reflectivity equations for multilayer systems. 
For the wavelength range of the measurements, the absorptive contributions embodied in $n$ were negligibly small for all the layers and $k$ was set to zero for the models. For the wavelength-dependent values of $n$ for some of the materials, we used a three-term Cauchy model ( $C$ in Eq. 1 is not related to concentration $)^{71,72}$ :

$$
n(\lambda)=A+\frac{B}{\lambda^{2}}+\frac{C}{\lambda^{4}}
$$

For bare silicon wafer, treated with oxygen plasma, the known values of $n(\lambda)$ for $\mathrm{SiO}_{2}$ were used. For the undecylaldehyde acetal layers, we used the published values of the wavelength dependent refractive indexes for alkanes for initial guesses for $A, B$, and $C \cdot{ }^{34}$ For polyethylene glycol, the reported values of $B$ and $C$ are significantly smaller than $A,{ }^{19}$ making the nonlinear terms (i.e., second and third term) in Eq. (1) statistically insignificant for the data fits for substrates with PEG layers.

Ellipsometry measurements for acetal-derivatized silicon revealed that upon treatment with oxygen plasma, the silicon wafers were covered with about $2 \mathrm{~nm}$ layer of silicon dioxide. The data from the silanized substrates could not be fit to a single-layer model. A twolayer model, encompassing a layer of $\mathrm{SiO}_{2}$ and a layer of the alkyl material over it, yielded a thickness of 1.0 $( \pm 0.3) \mathrm{nm}$ for the undecylaldehyde acetal layer.

For PEG-derivatized surfaces, the ellipsometry data indicated the average thickness of the polymer layers is $11( \pm 0.2) \mathrm{nm}$. Based on reported PEG density (1.1$\left.1.2 \mathrm{~g} / \mathrm{cm}^{3}\right),{ }^{44,56}$ and the molecular weight of the macromolecules $\left(M W_{\mathrm{PEG}}=2 \mathrm{kDa}\right)$, the surface concentration was calculated to be $3.5( \pm 0.6)$ PEG molecules per $\mathrm{nm}^{2}$. For previously reported procedures for grafting PEG chains to surfaces of substrates such as silica or gold, the packing density of PEGs ( $M W$ larger than about $0.5 \mathrm{kDa}$ ) was less than one molecule per $\mathrm{nm}^{2}{ }^{46,53,77}$

We believe that this approach for estimation of the PEG density, which we and others have used, ${ }^{46,53,77}$ leads to overestimation because of two principal reasons. (1) We and others assume that the PEG molecules are attached to substrate surfaces that atomically flat over the area of measurement (the illumination spot for ellipsometry measurements is in the order of $1 \mathrm{~mm}^{2}$ or larger). Even for smooth surfaces, on areas of less than $1 \mu \mathrm{m}^{2}$, the granulate nature of the substrates (such as gold films) has to be taken under consideration. The true coated areas, therefore, are larger than what is considered in the estimation, leading to overestimation of the surface density. (2) The ellipsometry measurements are performed on dry surfaces: i.e., the PEGylated substrates are taken out of the aqueous environment, dried with a stream pure nitrogen, and placed on the spectrometer. Such drying process cannot completely dehydrate the PEG material. As a result, the measurements yield results for surface layers of contain hydrated polymers, overestimating the number of PEG molecules.

\section{Contact-Angle Measurements}

The wetting contact angles were measured using an automated EasyDrop instrument (Krüss), as we have previously reported. ${ }^{47}$

\section{Small-Angle Emission Measurements}

The emission spectra of GFP were recorded using a spectrofluorometer, Fluorolog-3-22, equipped with a 21-degree-angle collection adapter for surface-emission experiments. GFP-derivatized glass slides, with $R_{\mathrm{DM}}$ between 0 and 0.2 , were immersed in a cuvette filled with $3 \mathrm{~mL}$ PBS buffer, $\mathrm{pH}$ 6.85, and their emission and excitation spectra were recorded. For calibration, the fluorescence of PBS-buffered solutions of GFP with concentrations between 0 and $500 \mathrm{nM}$ were recorded under identical settings of the spectrofluorometer (Figs. 2a and 2b). The fluorescence intensities, $F$, measured for the calibration solutions with different concentrations of GFP were fitted to Eq. (3) (Figs. 2c and 2d). ${ }^{14}$ The obtained parameter $F_{0}$ and $\alpha$ were input in Eq. (4) for calculation of the GFP surface concentration.

From the emission intensities, $F_{\mathrm{S}}$, recorded for GFP immobilized on glass slides with different $R_{\mathrm{DM}}$, the corresponding surface concentrations of the protein, $\Gamma_{\text {GFP }}$ (in molecules $/ \mathrm{nm}^{2}$ ) were calculated using Eq. (4) (Fig. 3). Each set of solution and surface measurements were collected with identical settings of the spectrofluorometer within 3-6 h period. The obtained surface concentrations, $\Gamma_{\mathrm{GFP}}$, were plotted against $R_{\mathrm{DM}}$ and fitted to a sigmoidal function (Fig. 3b).

\section{Kinetic Measurements}

The kinetic assays for the BCA enzyme were carried with a Varian Cary (scanning wavelength) UV/Visible spectrophotometer. For homogeneous catalysis, the cuvette was filled with 3-mL BCA solutions with different concentration, between 0 and $10 \mu \mathrm{M}$. For heterogeneous catalysis, glass slides with BCA immobilized on them ( $R_{\mathrm{DM}}$ between 0 and 0.2$)$ were placed in a cuvette filled with three milliliters aqueous HEPES buffer, $\mathrm{pH}=8.25$. At time zero of the measurement, $30 \mu \mathrm{L}$ of $10 \mathrm{mM}$ solution of NPA was added and the solution was quickly stirred. The change in the absorption at $348 \mathrm{~nm}$ was recorded for $30 \mathrm{~min}$. The background absorbance at time zero was subtracted 

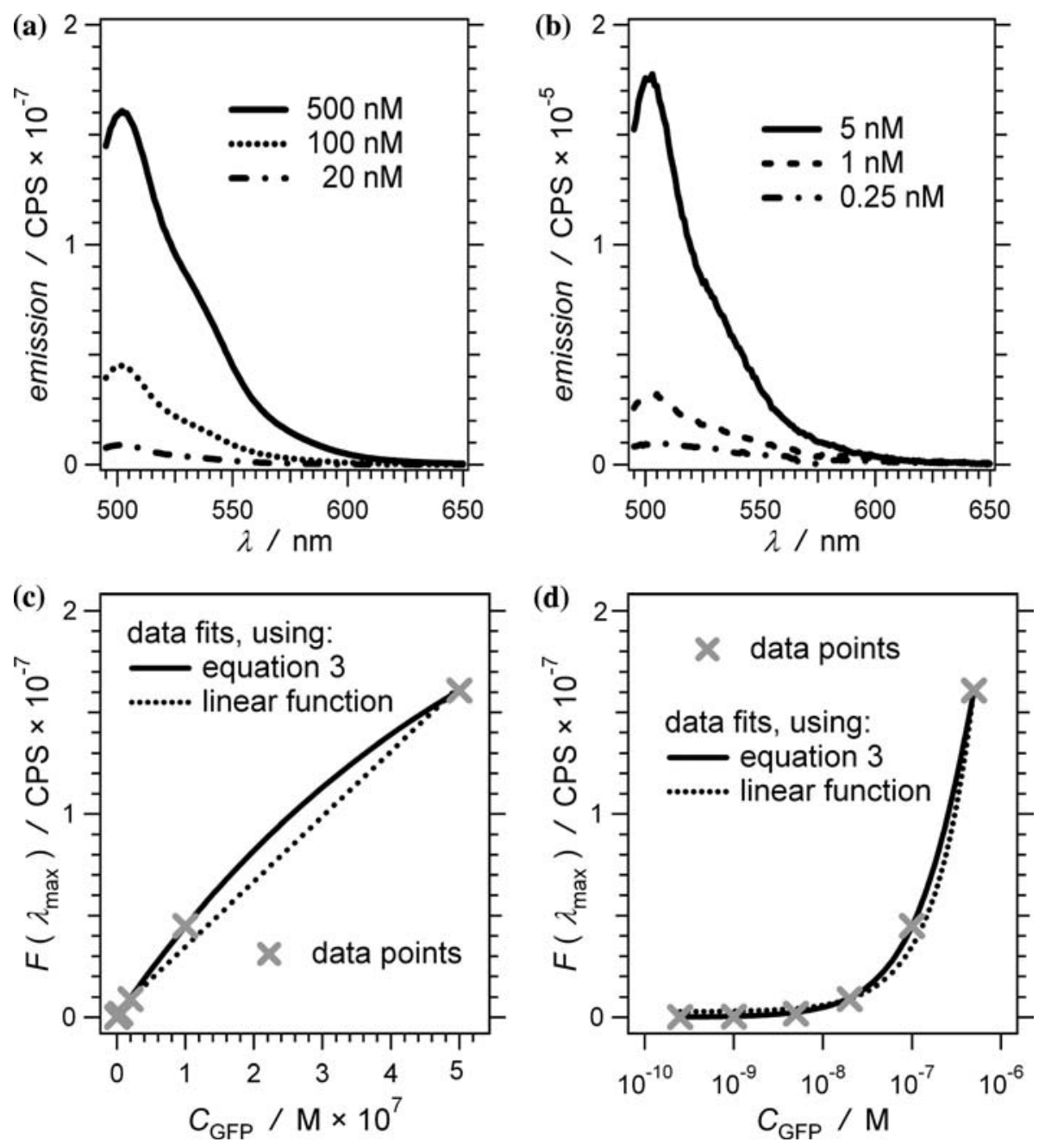

FIGURE 2. Fluorescence spectra of GFP solutions (PBS buffer, $\mathrm{pH}=6.85$ ) with different concentrations: (a) 20-500 $\mathrm{nM}$ and (b) $250 \mathrm{pM}-5 \mathrm{nM}\left(\lambda_{\mathrm{ex}}=480 \mathrm{~nm} ; \lambda_{\mathrm{em}}=495-650 \mathrm{~nm}\right)$. Dependence of the emission intensity at the maximum of the fluorescence band, $F\left(\lambda_{\max }\right)$, on the protein concentration, $\boldsymbol{C}_{\mathrm{GFP}}$, plotted against: (c) linear abscissa and (d) logarithmic abscissa. A linear function, $F\left(\lambda_{\max }\right)=a+b C_{\mathrm{GFP}}$, and Eq. (3) were used for fitting the data. Apparently, Eq. (3) yields a superior fit for this set of data that spans more than three orders of magnitude not only along the abscissa, but also along the ordinate.

from the data and the kinetic curves were divided by $5000 \mathrm{M}^{-1} \mathrm{~cm}^{-1}$, which is the molar extinction coefficient of both, nitrophenol and nitrophenolate, at $348 \mathrm{~nm}$ (Figs. 4a and 4b). ${ }^{14}$ From data fits of $C_{\mathrm{NP}}$ vs. time, the rate of formation of the product, nitrophenol(ate), NP, was extrapolated to time zero. The obtained initial rates, $v_{i}$, i.e., the rates at time zero, were plotted against $R_{\mathrm{DM}}$ and fitted to a sigmoidal function (Fig. 4c).

\section{RESULTS AND DISCUSSION}

\section{Surface Derivatization}

Using identical surface-chemistry procedures for glass and silicon substrates, we prepared a series of interfaces and investigated their properties. Due to the insufficient reflectivity of the glass, we conducted ellipsometry measurements only with the silicon samples. Because of the opacity of the silicon, UV/visible absorption and emission data were recorded solely for the glass-supported interfaces.

Although the two substrates, silicon and glass, have very different bulk properties, their surface composition can support similar types of chemistry. Silicon dioxide accounts for more than $70 \%$ of the content of the glass. The oxygen-plasma activation of the substrates, applied prior to the silanization, generates a thin layer $(\sim 2 \mathrm{~nm})$ of silicon dioxide on the silicon surfaces. Therefore, the discussed surface derivatization involves attachment of bioactive layers to silica, rather than silicon, interfaces. 

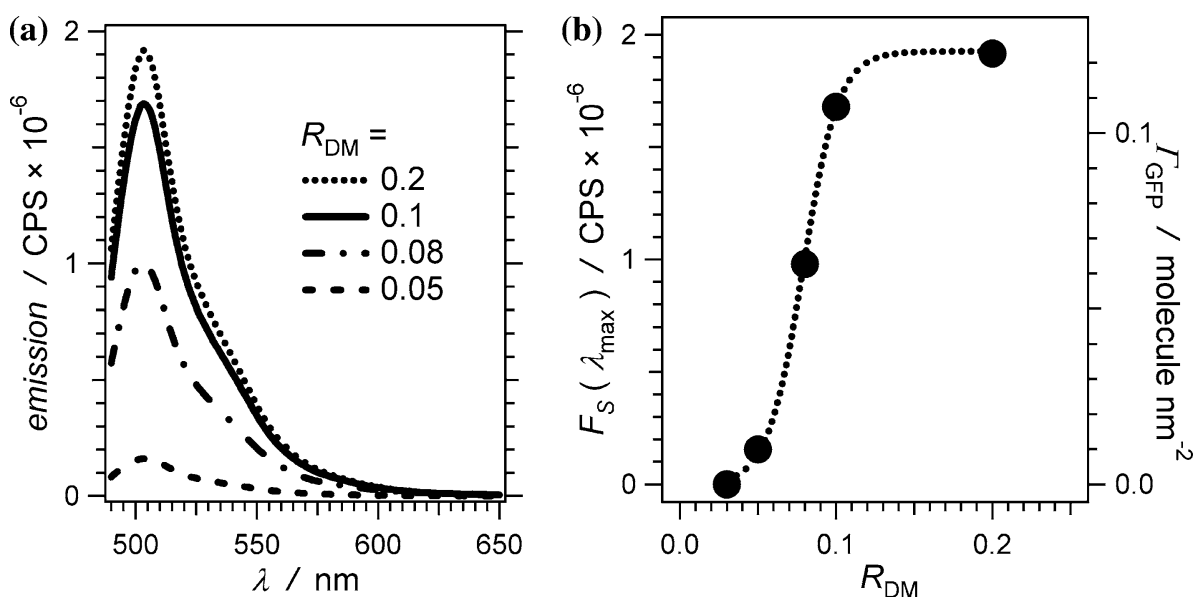

FIGURE 3. Fluorescence of surface-bound GFP. (a) Spectra of GFP attached to surfaces of glass slides coated with PEG at various $R_{\mathrm{DM}}$ ratios $\left(\lambda_{\mathrm{ex}}=480 \mathrm{~nm} ; \lambda_{\mathrm{em}}=490-650 \mathrm{~nm}\right)$. The glass slides were immersed in a PBS buffer $(\mathrm{pH}=6.85)$. $(\mathrm{b})$ Dependence of the emission intensity at the maximum of the fluorescence band, $F_{\mathrm{S}}\left(\lambda_{\max }\right)$, on the $R_{\mathrm{DM}}$ ratio. The corresponding GFP surface concentrations were calculated using Eq. (4). The parameters $F_{0}$ and $\alpha$, required for Eq. (4), were obtained from fitting solutionphase data (Fig. 2) with Eq. (3). The fluorescence data for solution-phase, $F\left(\lambda_{\max }\right)$, and surface-bound, $F_{\mathrm{S}}\left(\lambda_{\max }\right)$, GFP were recorded under identical settings of the spectrofluorometer within $3 \mathrm{~h}$ period.

\section{Considerations in the Strategy for Surface Derivatization}

Coating the surfaces with bioinert layers, prior to protein attachment, is essential step in the preparation of bioactive interfaces. Bioinert coatings provide: (1) resistance against nonspecific interactions; and (2) prevention of denaturation (and loss of activity) of the surface-bound proteins.

Polyethylene glycol (PEG) is the preferred polymer for constructing bioinert interfaces. The properties of polyethylene glycol make it unique among other watersoluble polymers. ${ }^{30,31}$ A small Flory-Huggins parameter and close-to-unity intramolecular expansion factor characterize the interactions of PEG with water. ${ }^{54}$ The amphipathic composition of this polyether, containing hydrophobic ethylene units $\left(-\mathrm{CH}_{2}-\mathrm{CH}_{2}-\right)$ and hydrogen-bond-accepting ether oxygens $(-\mathrm{O}-)$, appears to dictate its behavior and conformation in aqueous media. Other polyethers, such as polymethylene oxide (i.e., polyformaldehyde) and polypropylene oxide, for example, with higher or lower relative content of ether oxygens, respectively, are not water soluble. , $31,73^{2}$

Covalent attachment of polymers to silica-based surfaces can be performed in a single-step process (i.e., direct covalent attachment of the polymer to the substrate),${ }^{84}$ or via multiple-step procedures. ${ }^{17}$ While the single-step approaches for derivatization of surfaces are expedient, they are limited by the availability of polymer derivatives containing functional groups, such as alkoxysilyls, necessary for anchoring the macromolecules to the surfaces. Furthermore, solubility and conformational issues related to the polymer derivatives may limit the choice of media and conditions for conducting the single-step processes.
Alternatively, multiple-step approaches for derivatization of silica-based surfaces allow for significant flexibility and diversity in the types of coatings that can be prepared. Initial silanization of surfaces with small $\omega$-functionalized (trialkoxysilyl)alkanes, under optimal conditions for this particular reaction, can produce densely packed SAMs with functionality for covalent attachment of polymers onto them.

Two different approaches can be undertaken for preparation of polymer layers that are covalently attached to functionalized SAM surfaces: (1) polymerization at the SAM interface by introduction of monomers or prepolymers and initiation of the polymerization with the SAM functional groups ${ }^{57}$; and (2) covalent attachment of already synthesized polymers to the SAM functional groups. ${ }^{37,40,56}$ The second approach allows for considerably better control of the thickness and functionality of the formed coatings.

Not all high-yield solution-phase reactions are appropriate for surface derivatization. Reactions that proceed through bulky intermediates are hindered when forced to undergo at high-packing density onto heterogeneous interfaces. The immensely wide used carbodiimide chemistry for amide coupling, for example, should be employed with caution in surfacederivatization procedures due to the relatively large size of the active-ester intermediates. Therefore, we utilized silanization and reductive amination (both proceeding through intermediates with relatively small sizes) for achieving well packed PEGylated surfaces. The consequent steps of anchoring the proteins to the relatively flexible PEG chains at "diluted" surface concentrations do not have such steric restrictions. We, 

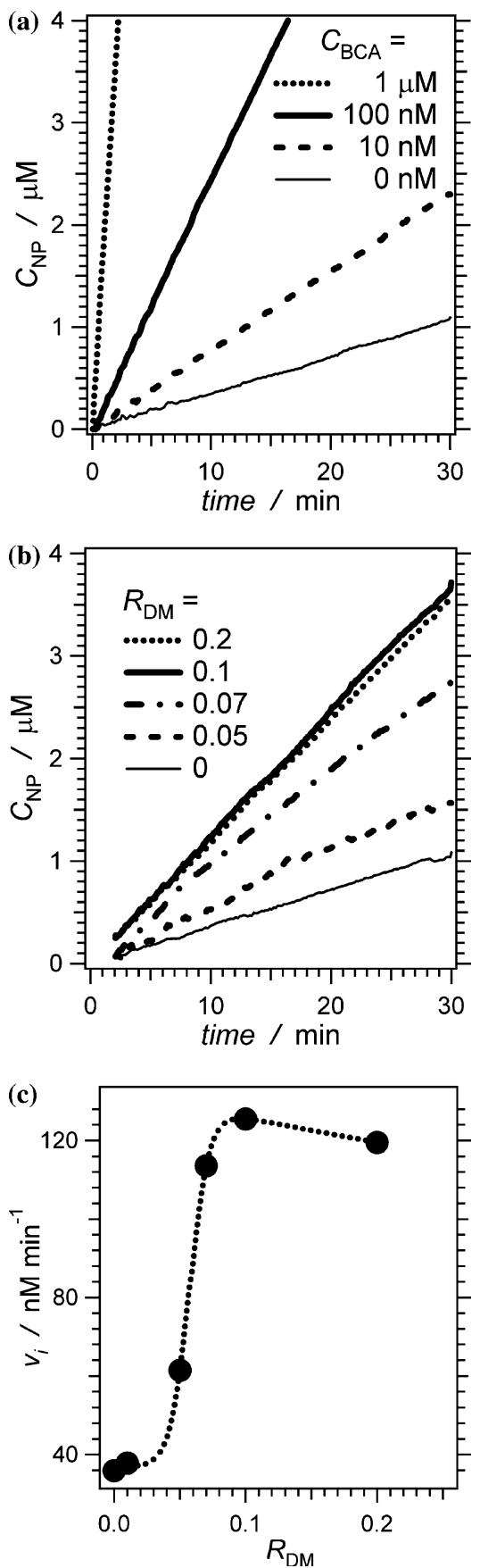

FIGURE 4. Enzymatic activity of BCA, catalyzing the hydrolysis of $0.1 \mathrm{mM}$ NPA in aqueous HEPES buffer ( $\mathrm{pH}=8.25$ ). (a) Homogeneous NPA hydrolysis, catalyzed by various concentrations of BCA dissolved in the solution. (b) Heterogeneous NPA hydrolysis, catalyzed by BCA immobilized on glass surfaces that were PEGylated at various RDM ratios. The glass slides were immersed in the NPA solution. (c) Dependence of the initial rate of hydrolysis, $v_{i}$, on $R_{\mathrm{DM}}$. The formation of NP (Scheme 2) was monitored via its absorption at $348 \mathrm{~nm}$. The blank solution (i.e., $C_{\mathrm{BCA}}=0$ ) and the blank PEGylated slides (i.e., $R_{\mathrm{DM}}=0$ ) manifested the same rates of non-catalyzed NPA hydrolysis indicating that the increase in the rates, observed for $R_{\mathrm{DM}}>0$, is due solely to the surfacebound enzyme and not to other components on the surfaces of the PEGylated glass. hence, employed cabodiimide chemistry for the last two chemical transformations.

We undertook a multiple-step approach for chemical derivatization of silica-based surfaces (Scheme 1). Each step was conducted under optimal conditions and in the most appropriate media for each particular reaction. We directly attached PEGs with molecular weight of about $2 \mathrm{kDa}$ to aldehyde-coated substrates, allowing amine functionality on the PEG layers. Conversion of amine to carboxyl functionality allowed for covalent attachment of proteins to the PEGylated surfaces via amide coupling.

\section{Silanization}

Due to their reactivity, aliphatic aldehydes present an excellent choice for preparation of chemically active surfaces. ${ }^{69}$ Their reactivity, however, can compromise the quality and durability of the formed active SAMs. Therefore, we chose to functionalize the substrates with acetals, i.e., protected aldehydes.

To suppress extensive crosslinking between the silyl conjugates in the SAMs, we silanized glass and silicon substrates under anhydrous conditions at elevated temperature for extended time periods: i.e., toluene, $\sim 110^{\circ} \mathrm{C}, \sim 12 \mathrm{~h}$. (Such crosslinking contributes to the formation of multilayers and defects in the surface coatings.) Furthermore, for obtaining coatings with improved quality, we chose alkoxysilyl derivatives as silanization agents, instead of the more reactive halosilyls. We observed, for example, that silanization with trichlorosilyls results in the formation of micrometersize multilayer aggregates that significantly increase the roughness of the surfaces. In comparison, identical silanization with trimethoxy- or triethoxysilyls yields lesser amount of smaller-size aggregates and hence, produces interfaces with smoother topography. ${ }^{83}$

In addition, we employed short mechanical treatments of the substrates within the first one-to-two hours of silanization. Examination with atomic force microscopy (AFM) and reflection interference contrast microscopy (RICM) showed that sonication for one minute at one hour after the initiation of the silanization, resulted in surface coatings with significantly decreased number of defects. ${ }^{83}$

The employed method under the discussed conditions of silanization with 11-(trietoxysilyl)undecanaldehyde acetal produced one-nanometers-thick coatings with acetal functionality (Scheme 1, i).

\section{Aldehyde Deprotection}

Conversion of acetals to aldehydes is typically carried in strong acidic media. Strong mineral acids, however, react with glass surfaces and hence, can wash 
away the SAMs. Moderately weak Lewis acids can catalyze acetal hydrolysis under relatively mild conditions. ${ }^{61}$ Adopting such an approach for aldehyde deprotection, allowed us to activate the acetal-coated substrates by converting the acetals to aldehydes using indium (III) ions, rather than mineral acid, as a catalyst (Scheme 1, ii). This treatment of the acetal-coated surfaces resulted in: (1) an increase in the relative content of the carbonyl carbons, as measured with XPS; and (2) a decrease in the wetting contact angle (with water) from $81^{\circ} \pm 6^{\circ}$ to $55^{\circ} \pm 14^{\circ}$. Both changes are consistent with the removal of the ethylene groups from the surface coating. We always conducted the surface activation, i.e., aldehyde deprotection, immediately before the next derivatization step.

\section{PEGylation}

Due to its simplicity and high yields, reductive amination is broadly used for anchoring of macromolecules to interfaces. Reductive amination occurs spontaneously at room temperature. Water, alcohols and other oxygen nucleophiles, typical for biological fluids, do not compromise the yields of reductive amination. ${ }^{4}$

This reaction between aldehydes and primary amines proceeds through small-size intermediates leading to the formations of imines. This initial amination step is reversible: i.e., the imines are readily hydrolysable. Reduction with hydride agents converts the imines to the final secondary amines that provide a stable carbonnitrogen-carbon covalent linkage. Overall, the reductive amination proceeds through intermediates that do not impose steric hindrance, and hence, it is appropriate for conducting high-yield coupling reactions at interfaces and for pursuing high-density packing.

For reducing agent, which converts the imines to the final amines making the coupling irreversible and unsusceptible to hydrolysis, we chose a hydride donor with moderate strength, sodium cyanoborohydride, ${ }^{4}$ to avoid possible side reactions and heating of the reaction mixture.

Covalent attachment of amine derivatives of PEGs (MW $\sim 2 \mathrm{kDa}$ ) to freshly deprotected aldehyde surfaces, via reductive amination, yielded polymer layers containing about three PEG molecules per $\mathrm{nm}^{2}$. Using mixtures of monoamine and $\alpha, \omega$-diamine polymers, $\mathrm{H}_{2} \mathrm{~N}-\mathrm{PEG}-\mathrm{O}-\mathrm{CH}_{3}$ and $\mathrm{H}_{2} \mathrm{~N}-\mathrm{PEG}-\mathrm{NH}_{2}$, respectively, allowed us to prepare PEG layers with free amines on their surfaces (Scheme 1, iii).

We used the molar fraction of the diamine in the reaction mixture, $R_{\mathrm{DM}}$, as a semi-quantitative indication of the expected amount of free amine groups on the surface:

$$
R_{\mathrm{DM}}=\frac{C_{\mathrm{H}_{2} \mathrm{~N}-\mathrm{PEG}-\mathrm{NH}}}{C_{\mathrm{H}_{2} \mathrm{~N}-\mathrm{PEG}-\mathrm{NH}_{2}}+C_{\mathrm{H}_{2} \mathrm{~N}-\mathrm{PEG}-\mathrm{O}-\mathrm{CH}_{3}}}
$$

where $C_{\mathrm{H}_{2} \mathrm{~N}-\mathrm{PEG}-\mathrm{NH}_{2}}$ and $C_{\mathrm{H}_{2} \mathrm{~N}-\mathrm{PEG}-\mathrm{O}-\mathrm{CH}_{3}}$ are the concentrations of the PEG diamine and monoamine, respectively, in the reductive amination reaction mixtures.

For the surface molar fraction of the primary amines, $\chi_{\mathrm{NH}_{2}}$, it can be assumed that $\chi_{\mathrm{NH}_{2}} \approx 2 R_{\mathrm{DM}}$ for $R_{\mathrm{DM}} \ll 1$ if: (1) all diamine polymer chains are anchored to the substrate via only one of their termini and (2) the amine groups at the termini of the monoand diamine polymers have identical reactivities. While increase in the length of the polymers should increase the plausibility of the latter condition, the flexibility of the PEG chains compromises the plausibility of the former condition. (The flexibility of the PEG chains increases the probability for the distal amine of a singly attached bifunctional polymer to come in contact with the interface.) Therefore, we expect $\chi_{\mathrm{NH}_{2}}<2 R_{\mathrm{DM}}$.

We used different reaction ratios, $R_{\mathrm{DM}}$, for coating aldehyde-activated surfaces. The primary amines at the PEG interface, however, do not provide means for direct covalent coupling to proteins without encountering undesirable side reactions. Therefore, we converted the amine functionality of the PEGylates substrates into carboxyl functionality by treatment of the substrates with preactivated 3,6,9-trioxaundecanedioic acid (Scheme 1, iv).

\section{Biofunctionalization}

Using amide coupling allowed for covalent attachment of proteins to the PEGylated interfaces. We activated the carboxylates at the PEG interfaces under anhydrous conditions (Scheme 1, v). Immediately after the activation, the substrates were transferred into an aqueous solution of the protein of interests, buffered at optimal pH (Scheme 1, vi).

Such an amide-coupling method for protein attachment presents two principal disadvantages: (1) depletion of positive surface charges of the protein (due to conversion of amines to amides) may change its functionality; (2) indiscriminate coupling to any of the amines (from surface lysines or $\mathrm{N}$-termini) will result in random orientations of the proteins at the PEGylated interfaces. Decrease in the surface concentration of the functional groups at the PEG interfaces will decrease the severity of the second issue. In fact, decrease in the surface concentration will assure that each protein molecule binds to the surface through only a single covalent bond, depleting only a single positive charge per a molecule. Furthermore, decrease in the surface concentration and increase in the length of the PEG linkers, which connect the biomolecules to the interface, will allow relatively free rotational diffusion of the proteins making the randomness of their binding to the substrate less of an issue. 
Nevertheless, we prepared substrates with a broad range of surface concentrations to examine if the functionalities of the interface-bound proteins are compromised. As a proof of principle, we immobilized two proteins with molecular weights of about $30 \mathrm{kDa}$ onto PEGylated glass and silicon substrates (Fig. 1). Small-angle emission spectroscopy allowed us to estimate the surface concentrations of green fluorescence protein (GFP) immobilized to the PEG interfaces prepared at various $R_{\mathrm{DM}}$ ratios. Alternatively, a surface-bound enzyme, bovine carbonic anhydrase II (BCA), exhibited activity catalyzing ester hydrolysis, which we observed using absorption spectroscopy.

\section{Small-Angle Fluorescence Studies}

Small-angle fluorescence spectroscopy allowed us to determine the surface concentration of GFP, $\Gamma_{\mathrm{GFP}}$, attached to PEGylated glass substrates. We used fluorescence spectra of solutions of GFP to generate the calibration curves required for the concentration measurements. The fluorescence intensities, $F$, measured for the calibration solutions with different concentrations of GFP were fitted to ${ }^{14}$ :

$$
F=F_{0}\left(1-10^{-\alpha C_{\mathrm{GFP}}}\right)
$$

where $F_{0}$ depends on the fluorescence quantum yield of GFP and the properties of the spectrometer; $C_{\mathrm{GFP}}$ is the solution concentration of GFP; and $\alpha$ is the product of the molar extinction coefficient of GFP at the excitation wavelength and the excitation pathlength.

Frequently the dependence of the fluorescence intensity on the fluorophore concentration is described as a liner relationship. Such linear representation, however, is an approximation. ${ }^{14}$ The failure of this approximation becomes particularly conspicuous for data with a broad dynamic range: i.e., for concentration ranges spanning a few orders of magnitude. Therefore, we chose to use the exact expression for $F$ vs. $C$, as shown on Eq. (3), that produced superior data fits in comparison with the linear approximation (Figs. 2c and 2d).

The similarities in the emission spectra of the surface-bound protein and the protein solutions indicate that a covalent attachment of GFP to PEGylated interfaces does not compromise its structural integrity and alter the microenvironment of its fluorophore (Fig. 5). From the emission intensities, $F_{\mathrm{S}}$, recorded for GFP immobilized on glass slides with different $R_{\mathrm{DM}}$ (Fig. 3), we calculated the corresponding surface concentrations of the protein, $\Gamma_{\mathrm{GFP}}$, using the calibration parameters $F_{0}$ and $\alpha$ (Eq. 3):

$$
\Gamma_{\mathrm{GFP}}=\frac{N_{A}}{\alpha 2 \times 10^{17}} \log \left(\frac{F_{0}}{F_{0}-F_{\mathrm{S}}}\right)
$$

where $N_{A}$ is the Avogadro's number, and the conversion factor, $2 \times 10^{17}$, yields $\Gamma_{\mathrm{GFP}}$ in molecules per $\mathrm{nm}^{2}$ if $C_{\mathrm{GFP}}$ in Eq. (3) is in moles per liter. The factor " 2 " in the denominator is introduced for transparent substrates, in which the front and the back surface are illuminated and both interfaces are sources of emission.

At small $R_{\mathrm{DM}}, \Gamma_{\mathrm{GFP}}$ increases relatively slowly with the increase in $R_{\mathrm{DM}}$ (Fig. 3b). Increase in $R_{\mathrm{DM}}$ above 0.05 causes a rapid increase in $\Gamma_{\mathrm{GFP}}$ with a rate, $\Gamma_{\mathrm{GFP}} /$ $R_{\mathrm{DM}}$, of about two molecules per $\mathrm{nm}^{2}$. For $R_{\mathrm{DM}}$ exceeding $0.1, \Gamma_{\mathrm{GFP}}$ plateaus at maximum value of about 0.13 molecules per $\mathrm{nm}^{2}$, which corresponds to an average surface area of about eight $\mathrm{nm}^{2}$ for a single GFP molecule.

Considering its dimensions, a single GFP molecule can cover an area between 7 and $15 \mathrm{~nm}^{2}$, corresponding to $0.07-0.14$ molecules per $\mathrm{nm}^{2}$. (GFP can be approximated to a cylinder with a diameter of about $3 \mathrm{~nm}$ and height of about $5 \mathrm{~nm}$, Fig. 1a.) Our findings suggest that at $R_{\mathrm{DM}} \geq 0.1$, GFP forms a tightly packed layer.

\section{Kinetic Assays}

Carbonic anhydrase is a zinc-containing metaloprotein that catalyzes the reversible conversion of carbon dioxide to carbonic acid (existing predominantly in the form of bicarbonate under physiological

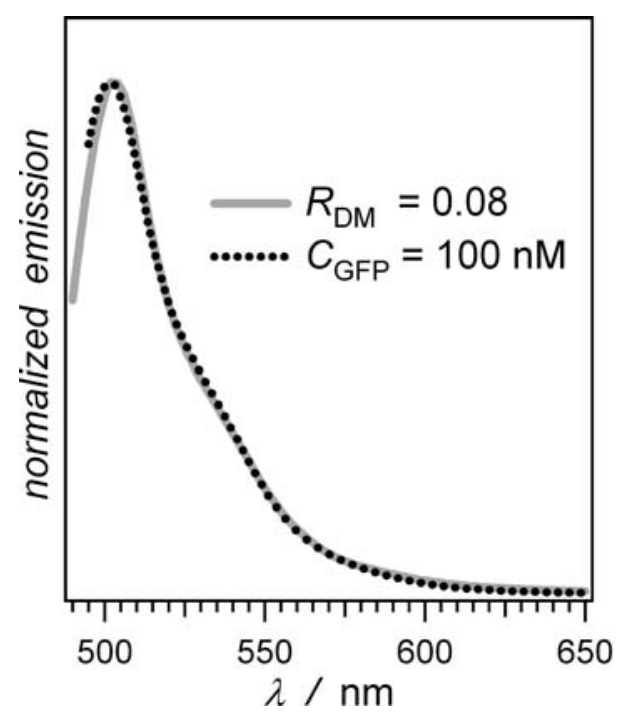

FIGURE 5. Overlap of the fluorescence spectra of GFP in solution $(100 \mathrm{nM})$ and bound to the surface of PEGylated glass slides $\left(R_{\mathrm{DM}}=0.08\right)$. The glass slides were immersed in a PBS buffer that is identical to the buffer used for the solution-phase GFP measurements $(\mathrm{pH}=6.85)$. The spectrum for the surface-bound protein was recorded between 490 and $650 \mathrm{~nm}$, while the spectrum for the solution-phase proteinbetween 495 and $650 \mathrm{~nm}\left(\lambda_{\mathrm{ex}}=480 \mathrm{~nm}\right)$. 
conditions). Carbonic anhydrase is also known to catalyze the hydrolysis of various aromatic esters. These processes occur at the same active site where the hydration of $\mathrm{CO}_{2}$ is catalyzed. We monitored the hydrolysis of 4-nitrophenyl acetate (NPA) in the presence and absence of BCA. ${ }^{75,81}$ The hydrolysis of NPA produces 4-nitrophenol (NP) and acetic acid. For the $\mathrm{pH}$ range, in which $\mathrm{BCA}$ is active, the nitrophenol is in equilibrium with nitrophenolate (Scheme 2). Using UV/visible absorption spectroscopy, we monitored the production of NP at $348 \mathrm{~nm}-$ a wavelength at which the protonated and deprotonated forms of NP have the same molar absorption extinction coefficients, $\varepsilon=5.0 \times 10^{3} \mathrm{M}^{-1} \mathrm{~cm}^{-1}$ (Figs. $4 \mathrm{a}$ and $4 \mathrm{~b}$ ). ${ }^{81}$

For homogeneous biocatalysis measurements, an increase in the solution concentration of BCA increased the rates of hydrolysis of NPA (Fig. 4a). For heterogeneous biocatalysis measurements, we immersed PEG-coated glass slides, with various amounts of BCA immobilized on their surfaces, into aqueous solutions of NPA. Indeed, we observed faster rates of hydrolysis when the glass slides were derivatized with higher surface concentration of BCA (Fig. 4b).

When the amount of substrate significantly exceeds the amount of enzyme, the initial rate of the catalyzed reaction, $v_{i}$, is linearly proportional to the concentration of the active enzyme. ${ }^{81}$ Comparison between the initial rates recorded for homogeneous and heterogeneous catalysis allowed us to estimate that the value of $v_{i}$ observed for $C_{\mathrm{BCA}}=10 \mathrm{nM}$ (Fig. $4 \mathrm{a}$ ) is in the range of the values of $v_{i}$ for $R_{\mathrm{DM}}$ between 0.05 and 0.07 (Fig. 4b). A consideration of the volumes of the samples and the areas of the coated surfaces, allows for estimations that indicate that enzyme volume concentration, $C_{\mathrm{BCA}}=10 \mathrm{nM}$, corresponds to enzyme surface concentration, $\Gamma_{\mathrm{BCA}}=0.04$ molecules per $\mathrm{nm}^{2}$. This estimation suggests that $\Gamma_{\mathrm{BCA}} \approx 0.08$ molecule $\mathrm{nm}^{-2}$ for the maximum rate of heterogeneous hydrolysis observed at $R_{\mathrm{DM}}=0.1$ (Fig. $4 \mathrm{c}$ ).

Despite their apparent plausibility (i.e., $\Gamma_{\mathrm{BCA}} \approx \Gamma_{\mathrm{GFP}}$ for identical $R_{\mathrm{DM}}$ ), the results from such estimation should be taken more like qualitative guidelines. A calculation of $\Gamma_{\mathrm{BCA}}$ from $C_{\mathrm{BCA}}$, based on enzymatic reaction rates, will result in underestimation of $\Gamma_{\mathrm{BCA}}$ because of the constraints inherent for the heterogeneous reactions: e.g., limits in enzyme diffusion and

NPA

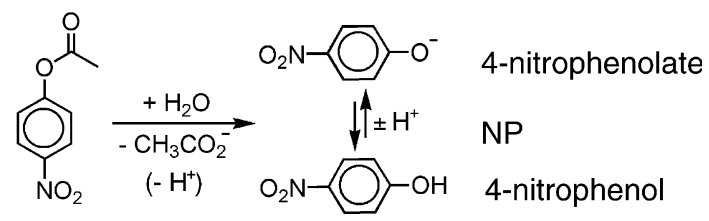

SCHEME 2. Hydrolysis of 4-nitrophenylacetate (NPA). mass transport at the bioactive interfaces. Nevertheless, the estimated values for $\Gamma_{\mathrm{BCA}}$, which are expected to be underestimated, are slightly smaller than the values for $\Gamma_{\mathrm{GFP}}$ at the same $R_{\mathrm{DM}}^{(\leq 0.1)}$. Because the surface concentrations of BCA were calculated from comparison between solution and heterogeneous kinetics, our findings suggest that the surface-bound BCA preserves its functionality for catalyzing ester hydrolysis.

For $R_{\mathrm{DM}}<\sim 0.1$, the dependence $v_{i}$ on $R_{\mathrm{DM}}$ showed a trend quite similar to the trend observed for the dependence of $\Gamma_{\mathrm{GFP}}$ on $R_{\mathrm{DM}}$ (Figs. $3 \mathrm{~b}$ and $4 \mathrm{c}$ ). Unlike GFP, however, the activity of surface-bound BCA reaches a maximum at $R_{\mathrm{DM}} \approx 0.1$ and consequently shows a decrease at higher values of $R_{\mathrm{DM}}$ (Fig. $4 \mathrm{c}$ ). Two different phenomena may contribute to the observed decline in BCA activity at $R_{\mathrm{DM}}$ exceeding 0.1 :

(1) The protein molecules are connected to the PEG interface via their surface amines and some of the lysine residues are in the proximity of the active site. Therefore, tight packing of the proteins on the surface, achieved at $R_{\mathrm{DM}} \approx 0.1$, may limit the accessibility to some of the active sites. Similar steric constraint may result from the formation of multiple covalent bonds between a single protein molecule and the interface at large $R_{\mathrm{DM}}$ values. Such multiple binding will impede the rotational diffusion of the enzyme molecules preventing an efficient exposure of their active sites to the solution.

(2) Acetic acid is a weak competitive inhibitor for carbonic anhydrase. Increase in the surface density of the enzyme may not allow an efficient diffusion of the produced acetate (Scheme 2) away from the interface. The observed decrease in BCA activity for relatively large $R_{\mathrm{DM}}$ values could be a reflection of partial inhibition resultant from increase in the local acetate concentration.

\section{Dependence of Protein Surface Concentration on $R_{D M}$}

For GFP and BCA, the dependence of the protein surface concentration, $\Gamma_{\mathrm{p}}$, on the reaction ratio, $R_{\mathrm{DM}}$, shows three distinct regions (Figs. $3 \mathrm{~b}$ and $4 \mathrm{c}$ ): (1) a slow increase in $\Gamma_{\mathrm{p}}$ with $R_{\mathrm{DM}}$ at $R_{\mathrm{DM}}<0.05$; (2) a sharp increase in $\Gamma_{\mathrm{p}}$ with $R_{\mathrm{DM}}$ at $0.05<R_{\mathrm{DM}}<0.1$; and (3) surface saturation, where $\Gamma_{\mathrm{p}}$ reaches the maximum at $R_{\mathrm{DM}}>0.1$.

At $R_{\mathrm{DM}} \approx 0.1$, maximum surface packing of the proteins is achieved. As expected, further increase in the surface concentration of carboxyl groups on the PEG layers will not result in increase in the protein surface concentration due to steric hindrance. The 
reasons for the nonlinear dependence of $\Gamma_{\mathrm{p}}$ on $R_{\mathrm{DM}}$, at $R_{\mathrm{DM}}<0.1$, resulting in two distinct regions, however, are not as obvious. The observed nonlinearity indicates that an increase in $R_{\mathrm{DM}}$ causes: (1) a nonlinear increase in the surface concentration of functional groups on the PEG layers; and/or (2) a nonlinear increase in the propensity for coupling of the proteins to the functionalized PEG layers.

In the described procedure, either one or both termini of the $\alpha, \omega$-diamines and dicarboxylates can attach to the surface layers (Scheme 1, iii and iv). The observed nonlinear dependence of protein surface concentration on $R_{\mathrm{DM}}$, therefore, could suggest that an increase in the molar ratio of the bifunctional conjugates in the reaction mixture, i.e., an increase in $R_{\mathrm{DM}}$, results in an increase in the portion of bifunctional conjugates that are surface-bound only through one of their termini.

A possible increase in the protein adsorptivity of the PEG interfaces with the increase in the amount of surface functional groups presents an alternative reason for the observed nonlinearity of $\Gamma_{\mathrm{p}}$ vs. $R_{\mathrm{DM}}$. Through the conversion of the PEG functionality to carboxyl, all primary amines on the PEG interface are transformed into amides (Scheme 1, iv), which may increase the surface adsorptivity for proteins. Furthermore, prior to the protein coupling, the carboxylic acid on the PEG surfaces is converted into an active ester, which is more hydrophobic than the carboxyl and methoxy groups. The increase in the surface fraction of amides and esters can lead to increase in the efficiency of the protein physisorption, which is the initial step of the chemical coupling reaction.

It is unlikely for electrostatic forces between the proteins and the deactivated carboxylates, which are negatively charged, to play a role in the increase in the physisorption propensity with the increase in $R_{\mathrm{DM}}$ because the isoelectric points of GFP and BCA have smaller values than the $\mathrm{pHs}$ of the buffers used for the coupling reactions. ${ }^{55,62}$

\section{CONCLUSIONS AND PERSPECTIVES}

The described multiple-step approach for preparation of PEG coatings for silica-based substrates involves relatively straightforward chemical transformations. Proteins, covalently attached to the PEGylated surfaces, demonstrated enzymatic and fluorescence properties similar to the properties of the same proteins dissolved in aqueous buffers.

The nonlinear relationships between functionalization parameters, such as $R_{\mathrm{DM}}$, and the protein surface concentrations provide guidelines for design and preparation of biofunctional and biocompatible interfaces. For example, the truly "diluted" surfaces, at relatively small $R_{\mathrm{DM}}$ values, present the useful range for single-molecule investigations. For such studies, intermolecular interference between neighboring surface-bound species is immensely detrimental. Small $R_{\mathrm{DM}}$ values, therefore, have the potential to decrease the probability of these types of undesired interactions, and hence, to make them statistically insignificant.

Alternatively, for significant bioactivity and celladhesion applications, well-packed interfaces at intermediate $R_{\mathrm{DM}}$ values can prove to be useful. As we demonstrated, however, the limits at maximum packing, imposed by the size of the immobilized proteins, present a risk of decline in the biological activity. A tight packing of the proteins against one another, in random orientation, limits the access to their active/ binding sites. If the orientation of covalent attachment of proteins to the surfaces cannot be controlled, they should be anchored via flexible linkers at distances from one another that will allow free access to their binding sites, and hence, no obstruction of the desired bioactivity and interactions. The type of biofunctionality and desired interactions dictate the optimal distance between proteins on such bioactive coatings. For interactions with small molecules, for example, separation of about a nanometer (or less) between the surface-bound proteins may be sufficient for reasonable access to their active sites. For interactions with biopolymers and other macromolecules, on the other hand, the surface-bound proteins should be distributed several nanometers away from one another in order to assure free access to the binding sites and to prevent any undesired steric hindrance.

While silica-based materials are prevalently utilized for bone regeneration and drug delivery, ${ }^{78}$ we believe that the described approach for surface biofunctionalization can readily be expanded to a broad range of substrates with biomedical importance. The silanization reaction (Scheme 1,i) provides the initial covalent attachment of the coatings to the silica-based substrates. A change in the substrate material will, indeed, require an alternative initial reaction. The rest of the chemical-transformation steps, however, can be adopted without significant modification.

\section{ACKNOWLEDGMENT}

Support for this work was provided by US Department of Education, UC Energy Institute, and UCR Academic Senate. 


\section{OPEN ACCESS}

This article is distributed under the terms of the Creative Commons Attribution Noncommercial License which permits any noncommercial use, distribution, and reproduction in any medium, provided the original author(s) and source are credited.

\section{REFERENCES}

${ }^{1}$ Andrade, J. D., and V. Hlady. Protein adsorption and materials biocompatibility: a tutorial review and suggested hypotheses. Adv. Polym. Sci. 79:1-63, 1986.

${ }^{2}$ Anselmo, A. G., R. C. Sassonia, and W. Loh. Thermodynamics of the partitioning of poly(propylene oxide) between aqueous and chlorinated organic phases compared to poly(ethylene oxide) and other hydrophilic polymers. $J$. Phys. Org. Chem. 19:780-785, 2006. doi:10.1002/poc.1079. ${ }^{3}$ Barber, S. M., P. J. Costanzo, N. W. Moore, T. E. Patten, K. S. Lancaster, C. B. Lebrilla, and T. L. Kuhl. Bilateral, difunctional nanosphere aggregates and their assembly mediated by polymer chains. J. Phys. Chem. A 110:45384542, 2006. doi:10.1021/jp0560617.

${ }^{4}$ Baxter, E. W., and A. B. Reitz. Reductive aminations of carbonyl compounds with borohydride and borane reducing agents. Org. Reactions (New York) 59:1-714, 2002.

${ }^{5}$ Bayer, E. A., and M. Wilchek. Application of avidin-biotin technology to affinity-based separations. J. Chromatogr. 510:3-11, 1990. doi:10.1016/S0021-9673(01)93733-1.

${ }^{6}$ Begum, R., and H. Matsuura. Conformational properties of short poly(oxyethylene) chains in water studied by IR spectroscopy. J. Chem. Soc. Faraday Trans. 93:3839-3848, 1997. doi:10.1039/a703436i.

${ }^{7}$ Cha, T., A. Guo, and X.-Y. Zhu. Enzymatic activity on a chip: the critical role of protein orientation. Proteomics 5:416-419, 2005. doi:10.1002/pmic.200400948.

${ }^{8}$ Chapman, R. G., E. Ostuni, S. Takayama, R. E. Holmlin, L. Yan, and G. M. Whitesides. Surveying for surfaces that resist the adsorption of proteins. J. Am. Chem. Soc. 122:8303-8304, 2000. doi:10.1021/ja000774f.

${ }^{9}$ Chen, C. S., M. Mrksich, S. Huang, G. M. Whitesides, and D. E. Ingber. Geometric control of cell life and death. Science 276:1425-1428, 1997. doi:10.1126/science.276. 5317.1425

${ }^{10}$ Chen, S., L. Liu, and S. Jiang. Strong resistance of oligo(phosphorylcholine) self-assembled monolayers to protein adsorption. Langmuir 22:2418-2421, 2006. doi:10.1021/la052851w.

${ }^{11}$ Chen, S., J. Zheng, L. Li, and S. Jiang. Strong resistance of phosphorylcholine self-assembled monolayers to protein adsorption: insights into nonfouling properties of Zwitterionic materials. J. Am. Chem. Soc. 127:14473-14478, 2005. doi: $10.1021 / \mathrm{ja} 054169 \mathrm{u}$.

${ }^{12}$ Chien, S. Mechanotransduction and endothelial cell homeostasis: the wisdom of the cell. Am. J. Physiol. 292:H1209-H1224, 2007.

${ }^{13}$ Chien, S., S. Li, Y.-T. Shiu, and Y.-S. Li. Molecular basis of mechanical modulation of endothelial cell migration. Front. Biosci. 10:1985-2000, 2005. doi:10.2741/1673.

${ }^{14}$ Crosby, G. A., and J. N. Demas. Measurement of photoluminescence quantum yields. Review. J. Phys. Chem. 75:991-1024, 1971. doi:10.1021/j100678a001.
${ }^{15}$ Dalsin, J. L., B.-H. Hu, B. P. Lee, and P. B. Messersmith. Mussel adhesive protein mimetic polymers for the preparation of nonfouling surfaces. J. Am. Chem. Soc. 125:42534258, 2003. doi:10.1021/ja0284963.

${ }^{16}$ Deng, L., M. Mrksich, and G. M. Whitesides. Self-assembled monolayers of alkanethiolates presenting tri(propylene sulfoxide) groups resist the adsorption of protein. J. Am. Chem. Soc. 118:5136-5137, 1996. doi:10.1021/ja960461d.

${ }^{17}$ Dominguez, M. M., M. Wathier, M. W. Grinstaff, and S. E. Schaus. Immobilized hydrogels for screening of molecular interactions. Anal. Chem. 79:1064-1066, 2007. doi: $10.1021 / \mathrm{ac} 061709 \mathrm{c}$.

${ }^{18}$ Evans, E. A. Force between surfaces that confine a polymer solution: derivation from self-consistent field theories. Macromolecules 22:2277-2286, 1989. doi:10.1021/ma00195a049.

${ }^{19}$ Ford, J. V., B. G. Sumpter, D. W. Noid, M. D. Barnes, and J. U. Otaigbe. Refractive index dispersion functions of solid-phase polymers by multicolor optical diffraction. Appl. Phys. Lett. 77:2515-2517, 2000. doi:10.1063/ 1.1318940 .

${ }^{20}$ Gong, P., and D. W. Grainger. Nonfouling surfaces a review of principles and applications for microarray capture assay designs. Methods Mol. Biol. 381:59-92, 2007. doi: 10.1007/978-1-59745-303-5 3 .

${ }^{21}$ Gong, X., L. Dai, H. J. Griesser, and A. W. H. Mau. Surface immobilization of poly(ethylene oxide): structure and properties. J. Polym. Sci. B: Polym. Phys. 38:23232332, 2000. doi:10.1002/1099-0488(20000901)38:17<2323:: AID-POLB120 > 3.0.CO;2-6.

${ }^{22}$ Gonnelli, M., and G. B. Strambini. No effect of covalently linked poly(ethylene glycol) chains on protein internal dynamics. Biochim. Biophys. Acta Proteins Proteomics 1794:569-576, 2009. doi:10.1016/j.bbapap.2008.12.005.

${ }^{23}$ Harbers, G. M., L. J. Gamble, E. F. Irwin, D. G. Castner, and K. E. Healy. Development and characterization of a high-throughput system for assessing cell-surface receptorligand engagement. Langmuir 21:8374-8384, 2005. doi: $10.1021 / 1 a 050396 y$.

${ }^{24}$ Harder, P., M. Grunze, R. Dahint, G. M. Whitesides, and P. E. Laibinis. Molecular conformation in oligo(ethylene glycol)-terminated self-assembled monolayers on gold and silver surfaces determines their ability to resist protein adsorption. J. Phys. Chem. B 102:426-436, 1998. doi: $10.1021 /$ jp972635z.

${ }^{25}$ Heilmann, K., T. Groth, M. Schossig, A. Lendlein, and B. Micheel. Modulation of hybridoma cell growth and antibody production by coating cell culture material with extracellular matrix proteins. Biochem. Eng. J. 35:301-308, 2007. doi:10.1016/j.bej.2007.01.035.

${ }^{26}$ Horbett, T. A. Principles underlying the role of adsorbed plasma proteins in blood interactions with foreign materials. Cardiovasc. Pathol. 2:137S-148S, 1993. doi:10.1016/ 1054-8807(93)90054-6.

${ }^{27}$ Horbett, T. A. The role of adsorbed proteins in animal cell adhesion. Colloids Surfaces B 2:225-240, 1994. doi:10.1016/ 0927-7765(94)80037-5.

${ }^{28}$ Horbett, T. A. Biological activity of adsorbed proteins. Surfactant Sci. Ser. 110:393-413, 2003.

${ }^{29}$ Horbett, T. A. The role of adsorbed proteins in tissue response to biomaterials. In: Biomaterials Science, 2 nd edn. New York: Elsevier Academic Press, 2004, pp. 237-246.

${ }^{30}$ Hui, S. W., T. L. Kuhl, Y. Q. Guo, and J. Israelachvili. Use of poly(ethylene glycol) to control cell aggregation and fusion. Colloids Surfaces B 14:213-222, 1999. doi:10.1016/ S0927-7765(99)00037-5. 
${ }^{31}$ Israelachvili, J. The different faces of poly(ethylene glycol). Proc. Natl. Acad. Sci. USA 94:8378-8379, 1997. doi:10.1073/ pnas.94.16.8378.

${ }^{32}$ Israelachvili, J. Differences between non-specific and biospecific, and between equilibrium and non-equilibrium, interactions in biological systems. Q. Rev. Biophys. 38:331337, 2005. doi:10.1017/S0033583506004203.

${ }^{33}$ Jonkheijm, P., D. Weinrich, H. Schroeder, C. M. Niemeyer, and $\mathrm{H}$. Waldmann. Chemical strategies for generating protein biochips. Angew. Chem. Int. Edit. 47:9618-9647, 2008. doi:10.1002/anie.200801711.

${ }^{34}$ Kerl, K., and H. Varchmin. Refractive index dispersion (RID) of some liquids in the UV/VIS between $20 \mathrm{DegC}$ and 60 DegC. J. Mol. Struct. 349:257-260, 1995. doi:10.1016/ 0022-2860(95)08758-N.

${ }^{35}$ Kikuchi, A., and T. Okano. Nanostructured designs of biomedical materials: applications of cell sheet engineering to functional regenerative tissues and organs. J. Control. Release 101:69-84, 2005. doi:10.1016/j.jconrel.2004.08.026.

${ }^{36}$ King, M. R., V. Heinrich, E. Evans, and D. A. Hammer. Nano-to-micro scale dynamics of P-selectin detachment from leukocyte interfaces. III. Numerical simulation of tethering under flow. Biophys. J. 88:1676-1683, 2005. doi:10.1529/biophysj.104.051805.

${ }^{37}$ Kingshott, P., J. Wei, D. Bagge-Ravn, N. Gadegaard, and L. Gram. Covalent attachment of poly(ethylene glycol) to surfaces, critical for reducing bacterial adhesion. Langmuir 19:6912-6921, 2003. doi:10.1021/la034032m.

${ }^{38}$ Klee, D., and H. Hocker. Polymers for biomedical applications: improvement of the interface compatibility. $A d v$. Polym. Sci. 149:1-57, 1999. doi:10.1007/3-540-48838-3 1.

${ }^{39}$ Knoner, G., B. E. Rolfe, J. H. Campbell, S. J. Parkin, N. R. Heckenberg, and H. Rubinsztein-Dunlop. Mechanics of cellular adhesion to artificial artery templates. Biophys. J. 91:3085-3096, 2006. doi:10.1529/biophysj.105.076125.

${ }^{40}$ La Flamme, K. E., K. C. Popat, L. Leoni, E. Markiewicz, T. J. La Tempa, B. B. Roman, C. A. Grimes, and T. A. Desai. Biocompatibility of nanoporous alumina membranes for immunoisolation. Biomaterials 28:2638-2645, 2007. doi:10.1016/j.biomaterials.2007.02.010.

${ }^{41}$ Lahiri, J., L. Isaacs, B. Grzybowski, J. D. Carbeck, and G. M. Whitesides. Biospecific binding of carbonic anhydrase to mixed SAMs presenting benzenesulfonamide ligands: a model system for studying lateral steric effects. Langmuir 15:7186-7198, 1999. doi:10.1021/la9815650.

${ }^{42}$ Laitinen, O. H., V. P. Hytonen, H. R. Nordlund, and M. S. Kulomaa. Genetically engineered avidins and streptavidins. Cell. Mol. Life Sci. 63:2992-3017, 2006. doi:10.1007/ s00018-006-6288-z.

${ }^{43}$ Leckband, D., S. Sheth, and A. Halperin. Grafted poly(ethylene oxide) brushes as nonfouling surface coatings. J. Biomater. Sci. Polym. Ed. 10:1125-1147, 1999. doi:10.1163/156856299X00720.

${ }^{44}$ Lin, Y. S., V. Hlady, and C. G. Golander. The surface density gradient of grafted poly(ethylene glycol): preparation, characterization and protein adsorption. Colloids Surfaces $B$ 3:49-62, 1994. doi:10.1016/0927-7765(93)01114-7.

${ }^{45}$ Love, J. C., L. A. Estroff, J. K. Kriebel, R. G. Nuzzo, and G. M. Whitesides. Self-assembled monolayers of thiolates on metals as a form of nanotechnology. Chem. Rev. 105:1103-1169, 2005. doi:10.1021/cr0300789.

${ }^{46}$ Metzger, S. W., M. Natesan, C. Yanavich, J. Schneider, and G. U. Lee. Development and characterization of surface chemistries for microfabricated biosensors. J. Vac. Sci. Technol. A 17:2623-2628, 1999. doi:10.1116/1.581921.
${ }^{47}$ Millare, B., M. Thomas, A. Ferreira, H. Xu, M. Holesinger, and V. I. Vullev. Dependence of the quality of adhesion between polydimethyl siloxane and glass surfaces on the conditions of treatment with oxygen plasma. Langmuir 24:13218-13224, 2008. doi:10.1021/la801965s.

${ }^{48}$ Moore, N. W., and T. L. Kuhl. Bimodal polymer mushrooms: compressive forces and specificity toward receptor surfaces. Langmuir 22:8485-8491, 2006. doi:10.1021/la0608462.

${ }^{49}$ Mrksich, M., J. R. Grunwell, and G. M. Whitesides. Biospecific adsorption of carbonic anhydrase to self-assembled monolayers of alkanethiolates that present benzenesulfonamide groups on gold. J. Am. Chem. Soc. 117:12009-12010, 1995. doi:10.1021/ja00153a029.

${ }^{50}$ Mrksich, M., and G. M. Whitesides. Using self-assembled monolayers to understand the interactions of man-made surfaces with proteins and cells. Annu. Rev. Biophys. Biomol. Struct. 25:55-78, 1996. doi:10.1146/annurev.bb.25. 060196.000415.

${ }^{51}$ Ochsenhirt, S. E., M. Tirrell, G. B. Fields, and A. K. Dillow. Use of supported thin films of peptide amphiphiles as model systems of the extracellular matrix to study the effects of structure - function phenomena on cell adhesion. In: Biomimetic Materials and Design, 2002, pp. 1-27.

${ }^{52}$ Ostuni, E., R. G. Chapman, R. E. Holmlin, S. Takayama, and G. M. Whitesides. A survey of structure-property relationships of surfaces that resist the adsorption of protein. Langmuir 17:5605-5620, 2001. doi:10.1021/ la $010384 \mathrm{~m}$

${ }^{53}$ Otsuka, H., Y. Nagasaki, and K. Kataoka. Characterization of aldehyde-PEG tethered surfaces: Influence of PEG chain length on the specific biorecognition. Langmuir 20:11285-11287, 2004. doi:10.1021/la0483414.

${ }^{54}$ Ozdemir, C., and A. Guner. Solution thermodynamics of poly(ethylene glycol)/water systems. J. Appl. Polym. Sci. 101:203-216, 2006. doi:10.1002/app.23191.

${ }^{55}$ Petermann, M. L., and N. V. Hakala. Molecular kinetic and electrophoretic studies on carbonic anhydrase. J. Biol. Chem. 145:701-705, 1942.

${ }^{56}$ Piehler, J., A. Brecht, R. Valiokas, B. Liedberg, and G. Gauglitz. A high-density poly(ethylene glycol) polymer brush for immobilization on glass-type surfaces. Biosens. Bioelectron. 15:473-481, 2000. doi:10.1016/S0956-5663(00) 00104-4.

${ }^{57}$ Popat, K. C., and T. A. Desai. Poly(ethylene glycol) interfaces: an approach for enhanced performance of microfluidic systems. Biosens. Bioelectron. 19:1037-1044, 2004. doi:10.1016/j.bios.2003.10.007.

${ }^{58}$ Popat, K. C., G. Mor, C. A. Grimes, and T. A. Desai. Surface modification of nanoporous alumina surfaces with poly(ethylene glycol). Langmuir 20:8035-8041, 2004. doi: 10.1021/la049075x.

${ }^{59}$ Popat, K. C., S. Sharma, and T. A. Desai. Quantitative XPS analysis of PEG-modified silicon surfaces. J. Phys. Chem. B 108:5185-5188, 2004. doi:10.1021/jp049260j.

${ }^{60}$ Qian, X., S. J. Metallo, I. S. Choi, H. Wu, M. N. Liang, and G. M. Whitesides. Arrays of self-assembled monolayers for studying inhibition of bacterial adhesion. Anal. Chem. 74:1805-1810, 2002. doi:10.1021/ac011042o.

${ }^{61}$ Ranu, B. C., R. Jana, and S. Samanta. A simple, efficient and general procedure for acetalization of carbonyl compounds and deprotection of acetals under the catalysis of indium(III) chloride. Adv. Synth. Catal. 346:446-450, 2004. doi:10.1002/adsc.200303154.

${ }^{62}$ Richards, D. P., C. Stathakis, R. Polakowski, H. Ahmadzadeh, and N. J. Dovichi. Labeling effects on the isoelectric 
point of green fluorescent protein. J. Chromatogr. A 853:21-25, 1999. doi:10.1016/S0021-9673(99)00687-1.

${ }^{63}$ Roberts, C., C. S. Chen, M. Mrksich, V. Martichonok, D. E. Ingber, and G. M. Whitesides. Using mixed selfassembled monolayers presenting RGD and (E.G) $3 \mathrm{OH}$ groups to characterize long-term attachment of bovine capillary endothelial cells to surfaces. J. Am. Chem. Soc. 120:6548-6555, 1998. doi:10.1021/ja972467o.

${ }^{64}$ Sato, R., K. Ueno, and H. Otsuka. Physicochemical characterization of PEG hydrogel to estimate biocompatibility. Trans. Mater. Res. Soc. Jpn. 33:775-777, 2008.

${ }^{65}$ Shang, H., and G. U. Lee. Magnetic tweezers measurement of the bond lifetime-force behavior of the IgG-protein a specific molecular interaction. J. Am. Chem. Soc. 129:6640 6646, 2007. doi:10.1021/ja071215c.

${ }^{66}$ Shankaran, D. R., K. V. Gobi, and N. Miura. Recent advancements in surface plasmon resonance immunosensors for detection of small molecules of biomedical, food and environmental interest. Sensor Actuator B: Chem. B121:158-177, 2007. doi:10.1016/j.snb.2006.09.014.

${ }^{67}$ Sharma, S., R. W. Johnson, and T. A. Desai. Evaluation of the stability of nonfouling ultrathin poly(ethylene glycol) films for silicon-based microdevices. Langmuir 20:348-356, 2004. doi: $10.1021 / 1 \mathrm{a} 0347531$.

${ }^{68}$ Shi, L. Biomimetic surfaces of biomaterials using mucintype glycoproteins. Trends Glycosci. Glycotechnol. 12:229239, 2000.

${ }^{69}$ Siow, K. S., L. Britcher, S. Kumar, and H. J. Griesser. Plasma methods for the generation of chemically reactive surfaces for biomolecule immobilization and cell colonization-a review. Plasma Processes Polym. 3:392-418, 2006. doi:10.1002/ppap.200600021.

${ }^{70}$ Slack, S. M., and T. A. Horbett. The Vroman effect. A critical review. ACS Symp. Ser. 602:112-128, 1995.

${ }^{71}$ Sultanova, N. G., I. D. Nikolov, and C. D. Ivanov. Measuring the refractometric characteristics of optical plastics. Opt. Quant. Electron. 35:21-34, 2003. doi:10.1023/ A:1021811200953.

${ }^{72}$ Tabet, M. F., and W. A. McGahan. Thickness and index measurement of transparent thin films using neural network processed reflectance data. J. Vac. Sci. Technol. A 17:1836-1839, 1999. doi:10.1116/1.581900.

${ }^{73}$ Talmud, S. L., N. P. Shpenzer, and V. K. Ridiger. Colloidal solubility of natural resins and synthetic high-molecularweight compounds in water. Dokl. Akad. Nauk SSSR 180:668-671, 1968

${ }^{74}$ Tao, F., and S. L. Bernasek. Understanding odd-even effects in organic self-assembled monolayers. Chem. Rev. 107:1408-1453, 2007. doi:10.1021/cr050258d.

${ }^{75}$ Thorslund, A., and S. Lindskog. Esterase activity and the anion inhibition of bovine zinc and cobalt carbonic anhydrases. Eur. J. Biochem. 3:117-123, 1967. doi:10.1111/ j.1432-1033.1967.tb19504.x.
${ }^{76}$ Tirrell, M., E. Kokkoli, and M. Biesalski. The role of surface science in bioengineered materials. Surf. Sci. 500:61-83, 2002. doi:10.1016/S0039-6028(01)01548-5.

${ }^{77}$ Uchida, K., H. Otsuka, M. Kaneko, K. Kataoka, and Y. Nagasaki. A reactive poly(ethylene glycol) layer to achieve specific surface plasmon resonance sensing with a high $\mathrm{S} / \mathrm{N}$ ratio: the substantial role of a short underbrushed PEG layer in minimizing nonspecific adsorption. Anal. Chem. 77:1075-1080, 2005. doi:10.1021/ac0486140.

${ }^{78}$ Vallet-Regi, M., and F. Balas. Silica materials for medical applications. Open Biomed. Eng. J. 2:1-9, 2008. doi:10.2174/ 1874120700802010001.

${ }^{79}$ Veiseh, M., O. Veiseh, M. C. Martin, F. Asphahani, and M. Zhang. Short peptides enhance single cell adhesion and viability on microarrays. Langmuir 23:4472-4479, 2007. doi:10.1021/1a062849k.

${ }^{80}$ Vericat, C., M. E. Vela, G. A. Benitez, J. A. M. Gago, X. Torrelles, and R. C. Salvarezza. Surface characterization of sulfur and alkanethiol self-assembled monolayers on Au(111). J. Phys. Condens. Mat. 18:R867-R900, 2006. doi:10.1088/0953-8984/18/48/R01.

${ }^{81}$ Verpoorte, J. A., S. Mehta, and J. T. Edsall. Esterase activities of human carbonic anhydrases B and C. J. Biol. Chem. 242:4221-4229, 1967.

${ }^{82}$ Vullev, V. I. Modulation of dissociation kinetics by external force: examination of the bell model. J. Biol. Sci. 5:744 $758,2005$.

${ }^{83}$ Wan, J. Functional Surface and Charge-transfer Arrays: Molecular Design and Device Fabrication. Ph.D. Dissertation, Boston University, 243 pp, 2007.

${ }^{84}$ Wolter, A., R. Niessner, and M. Seidel. Preparation and characterization of functional poly(ethylene glycol) surfaces for the use of antibody microarrays. Anal. Chem. 79:4529-4537, 2007. doi:10.1021/ac070243a.

${ }^{85}$ Woo, K. M., J. Seo, R. Zhang, and P. X. Ma. Suppression of apoptosis by enhanced protein adsorption on polymer/ hydroxyapatite composite scaffolds. Biomaterials 28:26222630, 2007. doi:10.1016/j.biomaterials.2007.02.004.

${ }^{86} \mathrm{Xu}, \mathrm{F}$., G. Zhen, F. Yu, E. Kuennemann, M. Textor, and W. Knoll. Combined affinity and catalytic biosensor: in situ enzymatic activity monitoring of surface-bound enzymes. J. Am. Chem. Soc. 127:13084-13085, 2005. doi:10.1021/ja050818q.

${ }^{87}$ Zhang, N., R. Schweiss, Y. Zong, and W. Knoll. Electrochemical surface plasmon spectroscopy-recent developments and applications. Electrochim. Acta 52:2869-2875, 2007. doi:10.1016/j.electacta.2006.10.060.

${ }^{88}$ Zwirbla, W., A. Sikorska, and B. B. J. Linde. Ultrasonic investigations of water mixtures with polyethylene glycols 200, 400 and ethylene glycol. J. Mol. Struct. 743:49-52, 2005. doi:10.1016/j.molstruc.2005.02.019. 